\title{
Mobile Care System for Older Adults: perceptions about its use in caring for people with dementia
}

\author{
André da Silva Brites ${ }^{1,2}$ (D) \\ Celia Pereira Caldas ${ }^{1,2}$ (D) \\ Luciana Branco da Motta ${ }^{1,2}$ (D) \\ Danielli Santos do Carmo ${ }^{2}$ ID \\ Alexandre Sztajnberg,4 $\mathbb{1 D}$ \\ Matheus Costa Stutzel 4 (D)
}

\section{Abstract}

Objective: To analyze the perceptions of caregivers and health professionals about a mobile application used for the caring and social support of people with dementia. Method: A qualitative study was performed on the experience of implementing a Mobile Care System for Older Adults (Sistema Móvel de Assistência ao Idoso, SMAI) in the routine of caregivers of people with dementia, treated at an outpatient clinic for cognitive disorders. Data were obtained through the application of questionnaires about the characteristics of caregivers and the Zarit scale to assess the level of burden. An Activities of Daily Living Questionnaire (ADLQ) was applied for functional evaluation. The perception of caregivers and professionals were collected through the audio recording of focus groups and analyzed according to the thematic-categorical analysis technique. Results: Twenty caregivers and five health professionals participated in the focus groups. Categories that emerged from the study revealed themes related to users' experiences, communication, medication management, feelings of caregivers, patient management strategies, impact of dementia on caregivers' lives, illness of caregivers and application evaluation. Conclusion: Interventions using mobile applications can help improve communication and social support in the care of dementia. The experience with the SMAI and its applications represented an innovative opportunity for both family caregivers and healthcare professionals.

1 Universidade do Estado do Rio de Janeiro (UERJ); Programa de Pós-Graduação em Ciências Médicas (PPGCM/UERJ). Rio de Janeiro, Rj, Brasil.

2 Universidade do Estado do Rio de Janeiro (UERJ); Núcleo de Atenção ao Idoso (NAI/UnATI/UERJ). Rio de Janeiro, RJ, Brasil.

3 Instituto de Matemática e Estatística (IME/UERJ); Departamento de Informática e Ciência da Computação; Programa de Pós-Graduação em Ciências Computacionais (CComp), Rio de Janeiro, Brasil.

4 Universidade do Estado do Rio de Janeiro (UERJ); Laboratório de Ciência da Computação (LCC/UERJ). Rio de Janeiro, Brasil.

Funding: Fundação de Amparo à Pesquisa do Estado do Rio de Janeiro (FAPERJ) - Edital no E-26/110.243/2014 e Coordenação de Aperfeiçoamento de Pessoal de Nível Superior (CAPES) - Bolsa de Doutorado no 88882.450494/2019-01.

The authors declare there are no conflicts of interest in relation to the present study.

Correspondence

Keywords: Communication. Caregivers. Health of the Elderly. Telemedicine. 


\section{INTRODUCTION}

Technologies designed to support people with dementia include the use of mobile devices that manage health care and strengthen the relationships between health professionals, family members and patients $^{1,2}$. The phenomenon of population aging has been accompanied by an increase in the number of people with dementia, generating a significant impact on the cost of care throughout life, and requiring interventions to provide support to families ${ }^{3}$.

An informal caregiver is described as an unpaid individual who performs non-professional care actions. This can be a family member, a friend or neighbor who provides assistance to dependent older adults in their daily activities ${ }^{4,5}$. Most of these caregivers have a family relationship with the older adults, in addition to physical and emotional proximity, and they are predominantly women.

Caring for a person with dementia has a significant impact on family dynamics. Care tasks range from supervising the older adult to helping with daily activities related to self-care such as personal hygiene, feeding, control of medication use and financial management. These activities can cause negative effects such as physical, psychological, social and financial burden ${ }^{6}$.

Health interventions carried out remotely represent a promising field of knowledge as well as supporting the care of dementia. Studies have highlighted the various forms of technology developed to care for this population group through tele-medicine ${ }^{7-9}$. Mobile applications are programs or software packages installed on smartphones with a friendly and attractive user interface. Health care is one of the main uses for apps, allowing monitoring of chronic diseases, the provision of guidance to caregivers and facilitating home monitoring systems ${ }^{10,11}$.

Several distance care interventions have been used to provide support to the family caregivers of people with dementia ${ }^{12}$. Types of technology related to the care of dementia can be classified as support in memory, treatment, safety, training, care and social interaction. Studies have highlighted the efficiency of mobile apps in providing health care to people with dementia, and in supporting their caregivers ${ }^{13-15}$.
The present study presents the experience of using the Mobile Care System for Older Adults (Sistema Móvel de Assistência ao Idoso, SMAI) and aims to analyze the perceptions of caregivers and health professionals about the use of the application in the care and social support of people with dementia.

\section{METHOD}

A qualitative study was carried out to evaluate the experience of using the SMAI app over an eighteen month period. Consolidated criteria for qualitative studies were used to plan and organize focus groups ${ }^{16}$. The study was carried out in a Geriatrics outpatient clinic and the sample was selected for convenience, rather than random, being composed of older adults and their caregivers, monitored from September 2015 to March 2017.

The following inclusion criteria were established: patients diagnosed with dementia and functional loss, treated at the geriatric outpatient clinic; the primary caregiver of the older people was interested in using the mobile app, and maintained direct contact with the older adults or formal caregiver. Patients who lived alone or in a Long Term Care Facility for older adults (LTCF) were not included. The health professionals included in the study were part of the multiprofessional team of the geriatric outpatient clinic and accompanied the older participants in face-to-face consultations.

The data were collected through questionnaires about the demographic and specific characteristics of the caregivers and the application of the Zarit scale, translated and adapted, to identify the level of burden of the caregivers ${ }^{17}$. To assess the patient's level of dependence, the Activities of Daily Living Questionnaire (ADLQ), used in the functional assessment of patients with Alzheimer's disease ${ }^{18}$, was applied.

\section{System Description}

The SMAI structure is composed of two Android mobile apps (SMAI Caregiver and SMAI Doctor), a web app (SMAI Web) and a server (the 
SMAI server). The apps were developed through a partnership between the geriatric outpatient clinic and the Computer Science Laboratory (CSL) of the Universidade do Estado do Rio de Janeiro (the State University of Rio de Janeiro, or UERJ).

The SMAI Web interface was developed with the objective of providing support to the health team through the monitoring of errors and data traffic, with the SMAI server responsible for the storage, authentication, access control and data transmission infrastructure of the apps.

A prior usability study was carried out with five caregivers selected at the clinic, in order to verify the behavior of the first prototype of the SMAI app. These caregivers used the prototype in real conditions for two weeks, evaluating the correct execution of the app and access to the remote database. Subsequently, the present study to assess perceptions was implemented with the second version of the app. Each participating caregiver received a Motorola Moto G smartphone, with the SMAI caregiver app installed and a SIM card with a data plan financed by the project, meaning there was no financial burden on participants during the study.

The SMAI includes features such as alerts for correct medication times, alarms, patient and caregiver reports, a facility for sending images, a GPS locator system and a space for exchanging messages between caregivers and medical staff. The patient report is organized in the form of a checklist containing information about sleep patterns, behavioral changes, eating habits, hydration, dysphagia, coughs, urine, bowel habits and a record of falls.

Health professionals monitored patients using a tablet with the "SMAI Doctor" version of the app installed, through which it was possible to view all the information sent by the caregivers individually.

In terms of data confidentiality, each user had a unique identification code within the system, which was authenticated before the sending and transmitting of data. All the data was encrypted to guarantee authenticity and confidentiality and communications sent by the health team were controlled by the identification (ID) of the respective professional.

\section{Organization of Focus Groups}

The perceptions of caregivers and professionals were analyzed using focus groups as a qualitative methodological strategy ${ }^{19}$. The meetings were conducted at the clinic, in a quiet place, free from distractions. They were audio recorded and lasted between 45 to 55 minutes. In addition to the participants, the main researcher attended as a facilitator, and an observer, who took notes during the focus groups, was present.

Three focus groups were organized after six, twelve and eighteen months of the use of the SMAI app by caregivers and the health team, as part of the continuity of distance care. In the first two meetings, open questions about the experience of using the system were asked. In the last meeting with the caregivers, closed questions were applied in order to focus on the evaluation of the system.

\section{Data Analysis}

The digital recordings were transcribed and the transcriptions were reviewed by the main researcher, who attended all the meetings. The data were analyzed using the thematic-categorical analysis $\operatorname{method}^{20}$. Content analysis is a communication analysis technique that reviews what is said in interviews and observed by researchers.

The first step, known as pre-analysis, includes the organization of the empirical material, and is represented by the literal transcription of the discourse. This process also includes an alternate reading and the definition of objectives, which supports the constitution of the textual corpus.

The exploration phase of the material begins through coding and decomposition in relation to the formulated objectives. In this step, the transformation of the data is observed through clipping, aggregation and enumeration techniques to achieve the representation of the content and the expression of the analyzed text. Finally, the material is classified into themes or categories that help to understand what lies behind the speeches ${ }^{21}$. 
The study was approved by the Research Ethics Committee under opinion no. 32654014.9.0000.5259. All the participants of the study signed an Informed Consent Term (ICF) and a Loan and Commitment Agreement for the device used in the study, containing information about the return of the device and procedures in case of loss or theft.

\section{RESULTS}

Twenty caregivers participated in the three focus group meetings, along with five health professionals (three physicians working in Geriatrics, one geriatrician and a social worker), all of whom accompanied the intervention study on the use of the system over an eighteen month period. Seven caregivers participated in the first focus group, the second meeting was attended by six caregivers, and seven caregivers participated in the final meeting. Tables 1 and 2 show the demographic and specific characteristics of the caregivers participating in the study, respectively.

There was a predominance of female, informal caregivers, who were married, had less than 12 years of schooling, a monthly income of 2 to 4 minimum wages, and who were retirees and daughters of the patients. Through the Zarit scale, a moderate to severe level of burden was identified, and the time spent as caregiver was up to 5 years. Most caregivers stated that they shared the care for the patient with another person in the family. Among the older participants, five $(25 \%)$ had moderate disability (25\%) and fifteen $(75 \%)$ severe disability, according to the scores obtained in the ADLQ, characterizing a significant degree of dependence for activities of daily living.

Table 1. Demographic characteristics of caregivers. Rio de Janeiro, 2015-2017.

\begin{tabular}{|c|c|}
\hline Characteristic & Caregivers $(n=20)$ \\
\hline Age & $67( \pm 10.75)$ \\
\hline \multicolumn{2}{|l|}{ Sex } \\
\hline Female & $18(90 \%)$ \\
\hline Male & $2(10 \%)$ \\
\hline \multicolumn{2}{|l|}{ Marital status } \\
\hline Married & $9(45 \%)$ \\
\hline Widow/widower & $1(5 \%)$ \\
\hline Divorced & $3(15 \%)$ \\
\hline Single & $7(35 \%)$ \\
\hline \multicolumn{2}{|l|}{ Education } \\
\hline$\leq 12$ years & $12(60 \%)$ \\
\hline$>12$ years & $8 \quad(40 \%)$ \\
\hline \multicolumn{2}{|c|}{ Family income (in minimum wages) } \\
\hline$\leq 2$ & $6(30 \%)$ \\
\hline $2-4$ & $12(60 \%)$ \\
\hline $4-6$ & $2(10 \%)$ \\
\hline$>10$ & $0(0 \%)$ \\
\hline \multicolumn{2}{|l|}{ Employment status } \\
\hline Employed & $2(10 \%)$ \\
\hline Unemployed & $2(10 \%)$ \\
\hline Retired & $16(80 \%)$ \\
\hline \multicolumn{2}{|l|}{ Kinship } \\
\hline Son/daughter & $15(75 \%)$ \\
\hline Spouse & $3(15 \%)$ \\
\hline Other & $2(10 \%)$ \\
\hline
\end{tabular}


Table 2. Specific characteristics of caregivers. Rio de Janeiro, 2015-2017.

\begin{tabular}{ll}
\hline Characteristic & Caregivers (n=20) \\
\hline Burden Level (Zarit) & $7(35 \%)$ \\
Moderate & $8(40 \%)$ \\
Moderate / Severe & $3(15 \%)$ \\
Severe & $2(10 \%)$ \\
Low/none & \\
\hline Time as caregiver & $9(45 \%)$ \\
$\leq 5$ years & $4(20 \%)$ \\
$6-7$ years & $4(20 \%)$ \\
$8-10$ years & $3(15 \%)$ \\
$>10$ years & \\
\hline Divides care & $11(55 \%)$ \\
Yes & $9(45 \%)$ \\
No & \\
\hline Lives with older adult & $18(90 \%)$ \\
Yes & $2(10 \%)$ \\
No & \\
Formal Caregiver & $4(20 \%)$ \\
Yes & $16(80 \%)$ \\
No & \\
\hline Health problems & $1(5 \%)$ \\
None & $11(55 \%)$ \\
1-2 2 & $8(40 \%)$ \\
\hline Psychological Support & \\
Yes & $6(30 \%)$ \\
No & $14(70 \%)$ \\
\hline
\end{tabular}

In the first meeting, communication with the health team was highlighted as a positive element in emergency situations, although the system was not designed for these cases. The comment about the reminder of the medication administration schedule indicated the need to update the prescriptions on the app screen after consultations at the clinic. Caregivers also expressed a feeling of security in their care through the use of the app (Table 3).

After 12 months, the caregivers highlighted the impact of dementia on their lives. When an interviewee talked about her life trajectory, dreams, projects and desires, it was noted that taking care of a person with functional dependence can have negative effects on the health of caregivers, especially when they are burdened. In addition to physical issues, social conflicts increase the complexity of care demands.

The observation of reports of caregiver burden and illness resulted in the referral of these people to the outpatient clinic to monitor their physical and emotional health. The importance of music therapy and leisure activities was highlighted when one of the caregivers said she had taken an older woman to cultural spaces she used to frequent. When talking about dementia, participants demonstrated concern about the progress of the disease. They also expressed satisfaction with the opportunity to exchange messages with the health team (Table 4). 
Table 3. Themes \& comments of caregivers after six months of use. Rio de Janeiro, 2015-2017.

\section{Theme 1: Communication}

- "She suffered a serious fall and we took her to the hospital, we recorded everything here. We were unable to resolve things with her doctor, because the appointment was scheduled for two or three months in the future. I sent messages and photos, then received the response, within the timescale" (Caregiver C5).

\section{Theme 2: Medication management}

- "The system sends a notification about the medication time, however, the medication registered is old and this worried me a little, and then it was confirmed. I sent a message about it"(Caregiver C2).

\section{Theme 3: Feelings of caregivers}

- "It has been very useful to ask the caregiver how they are feeling over the weekend, I think this is great. I just wanted to know what you do with it" (Caregiver C2).

- "I think I feel more secure when taking care of my mother, because every time I look, I find answers, I feel safer, so I use it a lot" (Caregiver C4).

- "So far, my experience has been very good, because it is very hard to be a caregiver, especially when you're alone, because it is only you taking care of that person" (Caregiver C7).

Table 4. Themes and comments from the health team. Rio de Janeiro. 2015-2017.

\section{Theme 1: Impact of dementia on the life of caregivers}

- "It affected my life 100\%. When I retired, my dream was to live my life and go backpacking. I have always enjoyed traveling, my life has changed from wine to water. There are days when I cry, it has also affected me financially" (Caregiver C4).

- "The impact on my life was that I lived on my own, I had my job, my car and my life. Now, due to my father's Alzheimer's disease, I have to stay at my mother's place more than at my own. Because he has stopped driving now, I sleep there so I can drive if anything happens" (Caregiver C2).

- "Alzheimer's disease scares me because I see that with my mother's case is advancing very quickly, she is becoming more agitated, depressed and is crying a lot. I use the smartphone all the time to send a message to the doctor" (Caregiver C3).

\section{Theme 2: Caregiver's illness}

- "I had high blood pressure, high glucose and serious spinal problems. There were days when I couldn't walk and with this stress the disease got worse" (Caregiver C4).

- "I had some aggravated problems like cholesterol, glucose and an increase in triglycerides and fibroids" (Caregiver C1).

- "My blood pressure and glucose are high now and I have trouble sleeping, sometimes I take pills. I was very angry and had no patience with anyone. My mother and I disagree a lot, she is very controlling and usually attacks me and offends me verbally" (Caregiver C2).

\section{Theme 3: Care strategies}

- "I put on the radio station that plays old and romantic songs. This week I put on spirituals, when I put on these songs she sings, dances and claps" (Caregiver C1).

- "Two years ago, we took her to a music club that played old songs, but she didn't react, she loved carnival" (Caregiver C5). 
After eighteen months, issues related to caregiver safety when using the app, communication and changes in daily care were observed, with emphasis on the exchange of messages with the health team (Table 5).

According to the SMAI Web interface the most frequently used functions were text messages, reminders about the administration of medication, appointment dates and the camera.

At the end of the intervention, the health professionals pointed out that some caregivers had difficulties attending consultations and the app allowed a closer relationship with the health team. They also agreed that the SMAI app would be very useful for patients with chronic conditions.
The patient report was considered repetitive and long for a daily task. Doctors highlighted the use of the system in the remote monitoring of patients with chronic conditions and mobility difficulties. In addition, they discussed the need to have a health professional responsible for managing the information transmitted by the mobile app in relation to the assessment of the treatment plan.

Adjustments were suggested for the third version of the SMAI Caregiver app, including simplifying the patient report. It was also observed that the messaging function was more prevalent than the others, as the caregivers expressed themselves more clearly and confidently. Finally, a change in the frequency of sending the patient report was suggested.

Table 5. Themes \& comments of caregivers after 18 months of use. Rio de Janeiro, 2015-2017.

\section{Theme 1: Caregiver safety}

- "I feel that I have my guardian angel, my companion, my security guard. The difference is the security. We feel more relaxed and safe, knowing that there is someone there all the time, instead of waiting three or four months "(Caregiver C1).

- "I felt much more secure" (Caregiver C5).

\section{Theme 2: Communication with the health team}

- "Communication with the doctors has improved. This is because we get a response almost immediately" (Caregiver C5).

- "The doctor who takes care of my mother at the hospital is always giving feedback and asking how she is doing with the app. Sometimes I send a text to the doctor. I even apologize sometimes, but I have to report everything that was happening to her" (Caregiver C2).

\section{Theme 3: Changes in daily care}

- "I have this obsession with caring, but one thing I find difficult is water. How many glasses, it asks. And then I started to supervise myself and it was good in that sense. Now I have this concern about water, in addition to medications, because I wasn't worried about it before like I am today" (Caregiver C4).

- "My mother hates drinking water. They say it is a common problem with older adults and the app asks how many glasses she drinks. These days I try to give my mother a lot more water" (Caregiver C3).

- "I used to pay more attention to coughing and urination, now I pay attention to the smell of her urine. One day my husband asked me: do you smell my mother's urine? I said: yes, of course, we need to see if it smells strong, because it could be a urinary tract infection. These two observations were excellent for me" (Caregiver C2). 
Table 6. Themes and comments from the health team. Rio de Janeiro. 2015-2017.

\section{Theme 1: Perceptions of the SMAI Doctor App}

- "I like the app. I find it very easy to use and patients can resolve small problems without having to make an appointment. They can resolve some very simple things, by sending and responding to messages, seeing something that is related to them" (P1, Resident in Geriatrics).

- "It is a very useful tool for monitoring these patients. Family members and caregivers have many important issues and burdens due to the type of care they provide. It also provides them with a certain degree of security when faced with an unexpected situation" (P2, Resident in Geriatrics).

- "Technology has brought many benefits to society and, in this case, it is extremely useful" (P3, Resident in Geriatrics).

\section{Theme 2: Positive points about the system}

- "They liked the app and felt accepted by our health team, feeling empowered to talk about their difficulties in the care process, so I think it works" (P5, Social Worker).

- "The technology broke a barrier that existed between us and the patient precisely because they are accessible to us all the time" (P3, Resident in Geriatrics).

\section{Theme 3: Negative points about the system}

- "They filled out or have to fill out the daily patient report. I think there were a lot of questions for them to fill out every day. There are many important things, but I think that responding every day probably causes some burden" (P1, Resident in Geriatrics).

- "The negative part is topics that can cause burden for the caregiver. If the app's intention is to alleviate this burden, it is a contradiction that they always have to answer a lot of questions" (P3, Resident in Geriatrics).

- "The patient's daily report is very detailed, however, it can become repetitive for the caregiver in their daily routine" (P5, Social Worker).

\section{Theme 4: My professional practice}

- "I would use it in my professional practice. It can be used for patients with Alzheimer's or other dementias, in palliative care and the monitoring of patients in home care" (P3, Resident in Geriatrics).

- "I wouldn't use it in a private consultation. I would use it in a situation where I have a multidisciplinary team. I have the impression that it is not really suitable for a private consultation" (P2, Resident in Geriatrics).

- "I think the biggest advantage of this app is to apply it in an institution like ours, which has a group of patients who need to be monitored clinically and among those who do not have direct access to doctors" (P4, Geriatrics).

- "I think it's great for monitoring complex patient groups across healthcare services. It is also very useful in situations such as home care"(P5, Social Worker).

\section{Theme 5: Solutions and ideas for the caregiver app}

- "I think that the most important issues are resolved by messages" (P2, Resident in Geriatrics).

- "It could be an app that the patient could download to their own smartphone. Currently, most people have a smartphone with various apps. I would like to have another colleague with me or a nurse to define the scheduling and message exchange functions" (P1, Resident in Geriatrics).

- "The messages are very important, but, on the other hand, we should make the app different from other apps, because messages can also be sent via WhatsApp, for example. Obviously, it is a health-related app, so this is already a differentiating factor. I also think it is important to keep the reports simplified" (P4, Geriatrics).

- "The big advantage is in terms of messages. I think we should value the qualitative space where we can express ourselves" (P5, Social Worker).

- "There could be an extra space for comments other than those requested daily, weekly or fortnightly" (P1, Resident in Geriatrics). 


\section{DISCUSSION}

The thematic analysis of the focus groups demonstrated that the systems implemented in the routine of caregivers and the health team had been accepted positively. The experiences of using the SMAI confirmed the hypothesis that interventions based on smartphones are effective, as they assist in the communication of caregivers with the health team, contributing to the therapeutic plan and the continuity of distance care ${ }^{22}$.

Communication through the SMAI app was highlighted by the caregivers, appearing in the first and third focus groups. However, although it had been agreed that the health team's response time would be 24 to 48 hours, some caregivers questioned the delay in response to some emergencies where the patient is at home. The system is aimed at the remote monitoring of patients and of interventions performed in face to face medical consultations, and does not include emergencies.

The study had certain limitations related to the reduced number of participants in the focus groups. The difficulty of gathering a larger number of participants was related to the lack of knowledge in the use of smartphones, as mentioned by the caregivers who refused the invitation to participate in the study. A study showed that factors such as age, sex and familiarity with technology influence participants when using technological devices ${ }^{23}$. In addition, the composition of the caregiver focus groups was not heterogeneous over the three meetings.

The system sent a notification at the exact time of the administration of medication, according to the registered medical prescription. It is necessary to update the medical prescription after each consultation. Care tools, such as medication reminders, facilitate adherence, in addition to monitoring adverse effects ${ }^{24}$. Low adherence to the daily sending of information was observed. Caregivers forgot to send the report or did not complete it correctly. For this reason, a more simplified report was suggested by the team.

The results showed that the use of a mobile app like SMAI can become a reality in the Brazilian health system. The need for an institutional structure with qualified personnel to manage remote interventions was described. Practical strategies such as skills training in health care management and the optimization of communication between caregivers and clinicians are considered potentially positive elements ${ }^{25}$.

Studies have shown that physicians are more open to being involved in the development of health apps and emphasize that public health programs should publicize such projects to maximize adherence to these types of technology ${ }^{26,27}$. However, the ease of developing and disseminating mobile apps should not mask the real challenges of applicability in clinical practice and the possible threats to patient safety.

\section{CONCLUSION}

The experience of implementing the SMAI app in the routine of family caregivers was an innovative opportunity for the geriatric outpatient clinic, offering social and clinical support, remote monitoring and professional guidance. In addition, a new dimension of care was observed in relation to feelings of loneliness and problems of burden and the illness of caregivers were identified.

The monitoring of patients by the health team made it possible to integrate technology into clinical practice. The perceptions of professionals about the SMAI Doctor app were positive. The exchange of messages was highlighted as a way of improving the communication options and social support of the caregiver.

Mobile apps are potentially useful in clinical practice when they value the health and social needs of patients and caregivers.

\section{ACKNOWLEDGMENTS}

The authors would like to thank the staff of LCC/ UERJ for their technical and scientific support, the graduating student Michel Pedro Filippo for his collaboration in the study, and the older adults, caregivers, professionals and medical residents of the NAI/UnATI/UERJ outpatient clinic.

Edited by: Ana Carolina Lima Cavaletti 


\section{REFERENCES}

1. Hall A, Wilson CB, Stanmore E, Todd C. Moving beyond 'safety' versus 'autonomy': a qualitative exploration of the ethics of using monitoring technologies in long-term dementia care. BMC Geriatr. 2019;19(145):1-13.

2. Brown EL, Ruggiano N, Li J, Clarke PJ, Kay ES, Hristidis V. Smartphone-Based Health Technologies for Dementia Care: Opportunities, Challenges, and Current Practices. J Appl Gerontol. 2017;38(1):73-91.

3. Lima-Costa MF, Peixoto SV, Malta DC, Szwarcwald CL, Mambrini JVM. Cuidado informal e remunerado aos idosos no Brasil (Pesquisa Nacional de Saúde, 2013). Rev Saúde Pública. 2017;51(Sup 1):1-6.

4. Rocha BMP, Pacheco JEP. Idoso em situação de dependência: estresse e coping do cuidador informal. Acta Paul Enferm. 2013;26(1):50-6.

5. Vieira CPB, Fialho AVM, Freitas CHA, Jorge MSB. Práticas do cuidador informal do idoso no domicílio. Rev Bras Enferm. 2011; 64(3):570-9.

6. Caldas CP, Moreira MD. A importância do cuidador no contexto da saúde do idoso. Esc Anna Nery Rev Enferm. 2007;11(3):520-5.

7. Jackson GA, Browne D. Supporting carers of people with dementia: what is effective? B J Psych Adv. 2017;23(3):179-86.

8. Sriram V, Jenkinson C, Peters M. Informal carers' experience of assistive technology use in dementia care at home: a systematic review. BMC Geriatr. 2019; 19(1):1-25.

9. Stutzel MC, Filippo MP, Costa RMEM, Sztajnberg A, Brites AS, Motta LB, et al. Multi-part quality evaluation of a customized mobile application for monitoring elderly patients with functional loss and helping caregivers. BMC Med Med Inform Decis Mak. 2019;19(40):1-18.

10. Wiklund Axelsson S, Nyberg L, Naslund A, Melander Wikman A. The Anticipated Positive Psychosocial Impact of Present Web-Based E-Health Services and Future Mobile Health Applications: An Investigation among Older Swedes. Int J Telemed Appl. 2013;1:1-9.

11. Rocha TAH, Fachini LA, Thumé E, Silva NC, Barbosa AC, Carmo MD, et al. Saúde Móvel: novas perspectivas para a oferta de serviços em saúde. Epidemiol. Serv Saúde. 2016;25(1):159-70.

12. Lorenz K, Freddolino PP, Comas-Herrera A, Knapp M, Damant J. Technology-based tools and services for people with dementia and carers: Mapping technology onto the dementia care pathway. Dementia. 2017;18(2):725-41.
13. Yousaf K, Mehmood Z, Saba T, Rehman A, Munshi AM, Alharbey R, et al. Mobile-health applications for the efficient Delivery of health care facility to People with Dementia (PwD) and support to their carers: a survey. BioMed Res Int. 2019;2019:1:1-26.

14. Quinn CC, Staub S, Barr E, Gruber-Baldini A. Mobile support for older adults and their caregivers: Dyad Usability Study. JMIR Aging. 2019;2(1):1-10.

15. Rathnayake S, Jones C, Calleja P, Moyle W. Family perspectives of managing activities of daily living and use of mHealth applications in dementia care: a qualitative study. J Clin Nurs. 2019;28(23-24):1-11.

16. Tong A, Sainsbury P, Craig J. Consolidated criteria for reporting qualitative research (COREQ): a 32-item checklist for interviews and focus groups. Int J Qual Health Care. 2007;9(6):349-57.

17. Queluz FNFR, Campos CRF, Santis L, Isaac L, Barham EJ. Zarit Caregiver Burden Interview: evidências de validade para a população brasileira de cuidadores de idosos. Rev Colomb Psicol. 2018;28(1):99-113.

18. Medeiros ME, Guerra RO. Tradução, adaptação cultural e análise das propriedades psicométricas do Activities of Daily Living Questionnaire (ADLQ) para avaliação funcional de pacientes com doença de Alzheimer. Rev Bras Fisioter. 2009;13(3):257-66.

19. Soares MI, Camelo SHH, Resck ZMR. A técnica de grupo focal na coleta de dados qualitativos: relato de experiência. Rev Min Enferm. 2016;20(1)1-5.

20. Silva AH, Fossá MIT. Análise de conteúdo: exemplo de aplicação da técnica para análise de dados qualitativos. Qualit@s Rev Eletr. 2015;16(1):1-14.

21. Bardin L. Análise de conteúdo. Portugal: EdiçõesTrês; 2010.

22. Waller A, Dilworth S, Mansfield E, Sanson-Fisher R. Computer and telephone delivered interventions to support caregivers of people with dementia: a systematic review of research output and quality. BMC Geriatr. 2017;17:1-20.

23. Sparkes J, Valaitis R, McKibbon A. A Usability Study of Patients Setting Up a Cardiac Event Loop Recorder and BlackBerry Gateway for Remote Monitoring at Home. Telemed J e.Health. 2012;18:484-90.

24. van Kerkhof LWM, van der Laar CWE, de Jong C, Weda M, Hegger I. Characterization of apps and other e-tools for medication use: insights into possible benefits and risks. JMIR. Mhealth Uhealth. 2016;4(2):1-14. 
25. Tremont G, Davis JD, Ott BR, Galioto R, Crook C, Papandonatos GD, et al. Randomized trial of the family intervention: telephone tracking caregiver for dementia caregivers: use of community and healthcare resources. J Am Geriatr Soc. 2017;65:924-30.
26. Jamwal NR, Kumar SP. Smarter palliative care for cancer: use of smartphone applications. Indian J Palliat Care. 2016;22:108-10.

27. Kuhn E, Eftekhari A, Hoffman JE, Crowley JJ, Ramsey KM, Reger GM, et al. Clinician perceptions of using a smartphone app with prolonged exposure therapy. Adm Policy Ment Health. 2014:41:800-7. 